Revista Eletrônica do Mestrado em Educação Ambiental

\title{
A EDUCAÇÃO AMBIENTAL NA FORMAÇÃO DO PEDAGOGO: a dimensão ambiental no curso de Licenciatura Plena em Pedagogia da UFPB - João Pessoa
}

Theoffillo da Silva Lopes ${ }^{1}$ Francisco José Pegado Abílio ${ }^{2}$

Resumo: Este artigo é proveniente de uma pesquisa que buscou investigar a dimensão ambiental inserida no curso de Pedagogia da Universidade Federal da Paraíba - Campus I. Para isso, foi utilizada uma metodologia qualitativa de abordagem documental/bibliográfica para análise do Projeto Político Pedagógico do curso, assim como também das ementas e programas das disciplinas do mesmo. Foram realizados ainda questionários semi-estruturados com professores e alunos do curso, a fim de assim, identificar como a dimensão ambiental vem sendo inserida no processo educativo de formação desses educadores e em que relação ela se estabelece entre o planejamento, a prática docente e o profissional formado.

Palavras - Chave: Educação Ambiental. Formação do pedagogo. Meio Ambiente.

\section{LA EDUCACIÓN AMBIENTAL EN LA FORMACIÓN DEL PEDAGOGO: la dimensión ambiental en el curso de Licenciatura Plena en Pedagogía de la UFPB - João Pessoa}

Resumen: Este artículo proviene de una investigación que buscó investigar la dimensión ambiental insertada en el curso de Pedagogía de la Universidad Federal de Paraíba - Campus I. Para ello, se utilizó una metodología cualitativa de abordaje documental / bibliográfico para análisis del Proyecto Político Pedagógico del curso , así como también de los menús y programas de las disciplinas del mismo. Se realizaron también cuestionarios semiestructurados con profesores y alumnos del curso, a fin de así identificar cómo la dimensión ambiental viene siendo insertada en el proceso educativo de formación de esos educadores y en qué relación se establece entre la planificación, la práctica docente y el desarrollo profesional formado.

Palabras clave: Educación Ambiental. Formación del pedagogo. Medio ambiente.

${ }^{1}$ Pedagogo da Universidade Federal da Paraíba, Especialista em Educação Ambiental, Mestre em Desenvolvimento e Meio Ambiente (PRODEMA/UFPB). Contato: theoffillo@outlook.com

${ }^{2}$ Professor Titular do Departamento de Metodologia da Educação, do Centro de Educação da Universidade Federal da Paraíba (UFPB). Bacharel em Ciências Biológicas pela UFPB (1994), Licenciado em Ciências Biológicas pela UFPB (2001), Mestre em Ciências Biológicas (Zoologia) pela UFPB (1997), Doutor em Ciências pela Universidade Federal de São Carlos (UFSCAR) (2002) e Pós-Doutor em Educação (Educação Ambiental) pela Universidade Federal de Mato Grosso (UFMT - 2011) sob a supervisão da Profa. Dra. Michèle Sato. Contato: chicopegado@ hotmail.com

Rev. Eletrônica Mestr. Educ. Ambient. Rio Grande, v. 36, n. 2, p. 296 - 318, mai./ago. 2019.

E-ISSN 1517-1256 


\title{
THE ENVIRONMENTAL EDUCATION IN THE TRAINING OF THE
}

PEDAGOGUE: the environmental dimension in the course of Full Degree in

Pedagogy of the UFPB - João Pessoa

\begin{abstract}
This article comes from a research that sought to investigate the environmental dimension inserted in the course of Pedagogy of the Federal University of Paraíba - Campus I. For this, a qualitative methodology of documentary / bibliographic approach was used to analyze the Political Pedagogical Project of the course, as well as the menus and programs of the disciplines of the same. Semi-structured questionnaires were also carried out with teachers and students of the course, in order to identify how the environmental dimension has been inserted in the educative process of formation of these educators and in what relation it is established between the planning, the teaching practice and the trained professional.
\end{abstract}

Keywords: Environmental Education. Formation of the pedagogue. Environment.

\section{Introdução}

Como ferramenta adotada para transpor a barreira das ações impensadas, a Educação Ambiental (EA) tem como escopo uma formação humana voltada a reconhecer o meio ambiente como parte essencial à vida humana como também qualquer outra forma de vida.

A EA apresenta em si uma nova roupagem a ser incorporada no campo da educação requerendo um engajamento pessoal, ativo, crítico e coletivo dos educadores e educandos objetivando desta forma um transformação não apenas de caráter social como também ambiental. Ou ainda como afirma (LAYRARGUES, 2006), que ela seja capaz de formar cidadãos socialmente justos, politicamente atuantes e ecologicamente corretos.

Compreendemos assim, a partir dessa reflexão inicial uma necessidade de se analisar a formação do pedagogo e sua relação com a EA, e ainda o seu papel perante tal realidade. Para tanto, este trabalho apresenta uma reflexão sobre obstáculos, ações e desafios vivenciados durante a formação do pedagogo analisado na Universidade Federal da Paraíba. Diante dessa realidade buscamos refletir sobre como a dimensão ambiental está inserida no currículo do curso de licenciatura em pedagogia. Cujo qual, nos apresentou como objetivos:

GERAL

- Realizar uma abordagem reflexiva sobre a relação entre meio ambiente e educação, e a dimensão ambiental inserida na formação do pedagogo.

ESPECÍFICOS:

Rev. Eletrônica Mestr. Educ. Ambient. Rio Grande, v. 36, n. 2, p. 296 - 318, mai./ago. 2019. 
- Investigar a dimensão ambiental inserida no currículo do curso de Pedagogia da Universidade Federal da Paraíba (UFPB) - Campus I;

- Analisar a temática ambiental presente transversalmente nas ementas e programas das disciplinas do curso;

- Conhecer a reflexão e discussão dos professores do curso sobre a temática ambiental inserida na educação;

- Identificar entre os alunos do curso de Licenciatura Plena em Pedagogia, oferecido pela UFPB, a percepção dos mesmos sobre a Educação Ambiental.

Pensar a dimensão ambiental inserida nos cursos de licenciatura e em especial em Pedagogia é essencial para a construção de uma sociedade ambientalmente emancipada, conhecedora dos seus direitos e deveres e consciente de suas ações sobre a natureza. Essa inserção se torna necessária à medida que encaramos os professores como mediadores da construção coletiva desse saber sobre o lugar do homem na natureza e suas relações com a mesma e entre si. Para tanto, é mister que os professores tenham contato a dimensão ambiental e as discussões sobre as problemáticas e busca de resoluções do tema desde o início de suas formações.

\section{Fundamentação}

Não podemos deixar de discutir a Educação aqui, partindo do pressuposto de que esse estudo que visa analisar sua função destinada a um determinado grupo, nesse caso, os pedagogos. Portanto, podemos repensar como e porque a educação se torna tão essencial para este estudo, uma vez que a relação que o homem estabelece com o meio ambiente perpassa pela via educativa. Com tudo isso educação se apresenta como plano de fundo para a construção da formação socioambiental que pode ser definida como sendo um conjunto de influências que sobre as nossas inteligências, independentemente de nossas vontades, exercem os outros, (DURKHEIM, 1978).Existe, portanto, vários sentidos para a educação, já em (FREIRE, 1997) observamos que a educação é um processo de comunhão entre os homens e o mundo, ou seja, os homens se educam entre si mediados pelo mundo. É conhecido ainda em (FREIRE, 1997) que educar é um ato político.

Em Brandão, no seu livro “O que é Educação ?” o autor afirma que:

Ninguém escapa da educação. Em casa, na rua, na igreja ou na escola, de um modo ou de muitos todos nós envolvemos pedaços da vida com ela: 
para aprender, para ensinar, para aprender -e -ensinar. Para saber, para fazer, para conviver, todos os dias misturamos a vida com a educação. Com uma ou com várias: educação? Educações. (...) Não há uma forma única nem um único modelo de educação; a escola não é o único lugar em que ela acontece e talvez nem seja melhor; o ensino escolar não é a única prática, e o professor não é seu único praticante. (BRANDÃO, 1981, p. 11)

Notamos então que a educação é, ao longo dos tempos, algo que vem sendo analisado teoricamente pela civilização humana. "Para o Estado a educação tem a finalidade de formar o cidadão, ou seja, dotar os mais jovens de condições básicas para desenvolver a cidadania.” (FERREIRA, 1993, p.22). Assim compreendemos a importância da educação para a vida, para as relações humanas, para o desenvolvimento dos indivíduos, lhes proporcionado a capacidade de transformar, de modificar as reais situações encontradas nas variadas sociedades humanas.

Baseando- nos nas citações que dizem respeito ao conceito de educação, torna-se claro que não devemos fechar os olhos e acreditar que o processo educativo está presente apenas na escola, deve-se também acreditar em programa de intervenção pedagógica não formal.Ou seja, a educação deve ser considerada sendo ela manifestada em toda e qualquer esfera social. Pois, como afirma (CARVALHO, 2002), o meio ambiente tomado enquanto um bem, pode tornar-se um ideal que pode mover militantes, orientar políticas e, sobretudo, instituir uma prática educativa específica.

\section{Metodologia}

A pesquisa foi desenvolvida no curso de Licenciatura Plena em Pedagogia da Universidade Federal da Paraíba, Campus I - João Pessoa, a fim de identificar a discussão, o conhecimento e reflexão dos alunos do curso sobre a Educação Ambiental. O estudo pretendeu realizar uma abordagem reflexiva sobre a relação existente entre o meio ambiente e a educação, e identificar essa relação na formação de pedagogos, investigando a discussão dos mesmos, dos professores do curso de Pedagogia, o currículo do curso e, ementas e programas das disciplinas.

Para tanto, foi utilizada uma metodologia qualitativa, de abordagem documental bibliográfica e também fenomenológica, de estudo das representações sociais e percepção ambiental (SATO, 2001). Segundo Sato, esse estudo descreve significados das experiências de vida sobre uma determinada concepção ou fenômeno, ou ainda estuda as 
representações de professores, analisando caminhos para implementação da Educação Ambiental.

O estudo foi aplicado através de análise do conteúdo (FRANCO, 2008) do currículo do curso de Pedagogia, buscando refletir criticamente sobre a dimensão das questões ambientais inseridas no mesmo. Assim, foi analisado o Projeto Político Pedagógico (PPP) do mesmo juntamente com o ementário das disciplinas, e também dos planos de curso das disciplinas, para verificar a inclusão da temática ambiental nestas.

Foi desenvolvido ainda um questionário semi-estruturado para aplicação aos professores do curso, buscando conhecer a percepção dos mesmos acerca dos temas ambientais, considerando que os mesmos são os formadores dos pedagogos. Nosso universo pesquisado contou com a presença de 14 professores, uma vez que o curso afirma ter 112 professores distribuídos nos três departamentos do Centro de Educação, a saber, Departamento de Fundamentação da Educação (DFE), Departamento de Metodologias da Educação (DME) e Departamento de Habilitações Pedagógicas (DHP).

Foi também aplicado um questionário semi-estruturado com um total de 120 alunos, distribuídos entre os primeiros e últimos períodos do curso, escolhido aleatoriamente entre os três turnos, para assim, avaliar a percepção dos alunos no início e no final do curso, acerca da percepção ambiental dos mesmos.

O universo da nossa pesquisa se apresentou da seguinte forma: $1^{\circ}$ período 20 alunos; $2^{\circ}$ período 4 alunos, $3^{\circ}$ período 25 alunos; $4^{\circ}$ período 2 alunos; $6^{\circ}$ período 19 alunos; $7^{\circ}$ período 13 alunos; $8^{\circ}$ período 13 alunos; 9 período 4 alunos e $11^{\circ} 1$ aluno, uma vez que o $9^{\circ}$ período se refere ao último período nos turnos da manhã e tarde com a duração de quatro anos e meio(4,5), enquanto os alunos do curso noturno têm sua conclusão no $11^{\circ}$, pois o mesmo tem sua duração de cinco anos e meio $(5,5)$.

\section{Resultados e discussão}

O Curso de graduação em Pedagogia tem como modalidade descrita em seu PPP a seguinte definição para a formação do pedagogo: Licenciatura em Pedagogia (Magistério em Educação Infantil e Séries Iniciais do Ensino Fundamental, cursos de Ensino Médio, na modalidade Normal e em outras áreas nas quais sejam previstos conhecimentos de caráter formador e pedagógico), tendo ainda como áreas de aprofundamento: Magistério em Educação de Jovens e Adultos e Educação Especial. 
Podemos observar durante a análise do PPP do Curso de Pedagogia da Universidade Federal da Paraíba (UFPB), Campus I - João Pessoa, que o mesmo afirma em suas linhas diretrizes que norteiam os princípios teóricos e metodológicos da prática educativa, e da reflexão sobre a formação e o fazer do pedagogo, considerando o seu compromisso social, e a preocupação em considerar as reais necessidades da sociedade atual.

No que diz respeito ao intuito da Licenciatura Plena em Pedagogia temos por objetivos:

- contribuir para a formação da consciência crítica dos futuros profissionais da educação;

- avançar na construção de uma teoria geral da educação;

- contribuir para a formação de profissionais que tenham condições de assumir a docência no campo da Educação Infantil e do Ensino Fundamental, e coordenar experiências pedagógicas em educação formal e não formal.

Ao analisar o PPP, pudemos observar que o mesmo trata-se de uma ferramenta de extrema pertinência e importância para o desenvolvimento do curso. Pois no mesmo, temos descritas todas as informações capazes de proporcionar uma melhor compreensão de como vem sendo realizada a prática de formação de pedagogos pela Universidade Federal da Paraíba. O mesmo justifica-se ainda como uma ferramenta que auxilia na melhoria da qualidade de ensino.

Dentro do PPP do curso de Pedagogia, podemos observar mesmo que de forma não tão presente, a inserção da temática ambiental em suas ideologias. Atendendo ao caráter transversal da dimensão, dentro da fundamentação teórica, o mesmo define alguns princípios para atender a uma abordagem pluralista da educação, e ainda parte da interdisciplinaridade para se alcançar esses princípios no processo educativo. É mencionado como um desses princípios:

Princípio de uma concepção de sociedade com maior justiça social, o que pressupõe melhor qualidade de vida, por meio de diferentes formas de pensar e atuar sobre a realidade, que se apresenta de modo multifacetado, plural e complexo.

A presença de características como justiça social, qualidade de vida, diferentes formas de pensar e atuar sobre a realidade e a complexidade, nos remete a que para isso, é necessário que o ser humano esteja em harmonia com o meio onde vive. Assim, esse 
princípio para o processo educativo, nos deixa aberto a possibilidade/necessidade da inserção da educação ambiental, para que se chegue ao fim desejado.

Isso se torna possível assim como afirma Bardin, no contexto em que "na altura da produção da palavra é feito um trabalho, é elaborado um sentido e são operadas transformações” (BARDIN, 2011, p. 218). Isso porque, tanto o discurso inserido no currículo, quanto o próprio currículo não é um material acabado ou imutável, mas está em constante transformação

Podemos ainda também recorrer à educação ambiental inserida nesse contexto das características de princípios da educação, pelo fato de a mesma, antes de tudo, ser Educação (LAYRARGUES, 2006). Assim, nenhuma discussão a respeito de metas, objetivos e princípios da educação, pode deixar de abordar a perspectiva da educação como um instrumento de produção/reprodução das condições sociais, das mudanças sociais.

Outro ponto encontrado no PPP do curso acerca da dimensão ambiental diz respeito às Competências, Atitudes e Habilidades que o profissional deve ter. Entre estas, destacase:

Demonstrar consciência da diversidade, respeitando as diferenças de natureza ambiental-ecológica, étnico-racial, de gêneros, faixa geracionais, classes sociais, religiões, necessidades especiais, escolhas sexuais, entre outras.

Especificamente nesse ponto, o Projeto Político Pedagógico do curso de Pedagogia da UFPB, reflete sobre a necessidade de o profissional em educação, obter em seus conhecimentos, os temas transversais, citando todos, entre eles, a dimensão ambiental.

Nesse ponto, no que diz respeito a respeitar as diferenças de natureza ambiental-ecológica, o PPP coloca em evidência o caráter da EA, que segundo (GUIMARÃES, 1995), deve ser realizar de forma diferenciada em cada meio para que se adapte às respectivas realidades, trabalhando com seus problemas específicos e soluções próprias em respeito à cultura, aos hábitos, aos aspectos psicológicos, às características biofísicas e socioeconômicas de cada localidade.

De acordo com o fluxograma do curso encontrado inserido no PPP em anexo, temos a grade curricular dividida em três bases: 1 - Educação e Sociedade; 2 Educação, Política e Trabalho; 3 - Educação e Prática Docente. Estas três bases definem a estrutura curricular do curso.

Com base nas respostas que buscamos encontrar nesta pesquisa, analisando o ementário, claramente podemos observar que durante o Curso de Pedagogia, dispomos 
apenas de uma disciplina intitulada de Corpo, Ambiente e Educação que maior contempla a dimensão ambiental.

Podemos observar ainda outras disciplinas que pela própria natureza podem vir a tratar de Educação Ambiental, como é o caso das disciplinas Ensino de Ciências Naturais na Educação Infantil e no Ensino Fundamental, e Ensino de Geografia para a Educação Infantil e Ensino Fundamental, que foram as únicas que apresentaram em seu plano de ementas tais características. Tais como: as categorias de análise de tempo, espaço, lugar, região, território, paisagem.

A ausência da Educação Ambiental nas demais ementas das disciplinas dispostas no PPP, de forma transversal e contextualizada com quaisquer que for a área de conhecimento, denuncia assim como nos remete (GUIMARÃES, 1995), a falta de integração entre diferentes saberes científicos, dificultando a melhor compreensão da realidade, que é integrada, formando uma totalidade.

O currículo do curso de Pedagogia da UFPB - Campus I está dividido em quatro partes. A saber, os Componentes Básicos Profissionais, compostos de 1.680h; os Componentes Complementares Obrigatórios, 1.140h; os Componentes Complementares Optativos, com um mínimo de 120h; e por fim, os Conteúdos Complementares Flexíveis, compostos de $270 \mathrm{~h}$. Estes últimos são exigidos em áreas específicas dos alunos, como participação em projetos de Iniciação à Docência, de Iniciação Científica, de Extensão, de Monitoria, ou ainda em participação de eventos com apresentação de trabalhos.

Vemos na tabela a seguir, as disciplinas que em seus programas, contemplam de forma transversal a temática ambiental, em que momento essas características aparecem, e o que elas contemplam acerca dessa temática.

\begin{tabular}{|c|c|c|c|}
\hline Disciplina & Base curricular & Tópico & Característica \\
\hline $\begin{array}{l}\text { Filosofia da } \\
\text { Educação II }\end{array}$ & $\begin{array}{l}\text { Componente } \\
\text { Básico } \\
\text { Profissional }\end{array}$ & $\begin{array}{l}\text { Problematização } \\
\text { Inicial }\end{array}$ & $\begin{array}{l}\text { O convite para o Curso inclui } \\
\text { um recuo no tempo para } \\
\text { revermos as heranças filosóficas } \\
\text { que prevaleceram com suas } \\
\text { concepções de mundo, de ser } \\
\text { humano, de sociedade e de } \\
\text { natureza capazes de orientar } \\
\text { modos de pensar e de agir. }\end{array}$ \\
\hline Sociologia da & Componente & Conteúdo & Educação ambiental e qualidade \\
\hline
\end{tabular}

Rev. Eletrônica Mestr. Educ. Ambient. Rio Grande, v. 36, n. 2, p. 296 - 318, mai./ago. 2019. 


\begin{tabular}{|c|c|c|c|}
\hline Educação II & $\begin{array}{l}\text { Básico } \\
\text { Profissional }\end{array}$ & $\begin{array}{l}\text { Programático - } \\
\text { Temas atuais da } \\
\text { Educação }\end{array}$ & de vida. \\
\hline $\begin{array}{l}\text { Psicologia da } \\
\text { Educação I }\end{array}$ & $\begin{array}{l}\text { Componente } \\
\text { Básico } \\
\text { Profissional }\end{array}$ & Objetivos & $\begin{array}{l}\text { Desenvolver a cidadania } \\
\text { cósmica, ou seja, a consciência } \\
\text { da responsabilidade } \\
\text { indivíduo na ecologia global que } \\
\text { inclui a humanidade, todos os } \\
\text { seres vivos da terra e do } \\
\text { universo. }\end{array}$ \\
\hline $\begin{array}{l}\text { Psicologia da } \\
\text { Educação II }\end{array}$ & $\begin{array}{l}\text { Componente } \\
\text { Básico } \\
\text { Profissional }\end{array}$ & Conteúdo & $\begin{array}{l}\text { Meio } \\
\text { Hereditariedade } \\
\text { Personalidade. }\end{array}$ \\
\hline $\begin{array}{l}\text { Ensino de } \\
\text { Ciências }\end{array}$ & $\begin{array}{l}\text { Componente } \\
\text { Básico } \\
\text { Profissional }\end{array}$ & $\begin{array}{l}\text { Seminários } \\
\text { Temáticos }\end{array}$ & $\begin{array}{l}\text { Terra e Universo; } \\
\text { Ar; } \\
\text { Água; } \\
\text { Solo; } \\
\text { Biodiversidade; } \\
\text { Ecologia; } \\
\text { Educação Ambiental. }\end{array}$ \\
\hline $\begin{array}{l}\text { Planejamento } \\
\text { Educacional }\end{array}$ & $\begin{array}{l}\text { Componente } \\
\text { Complementar } \\
\text { Obrigatório }\end{array}$ & $\begin{array}{l}\text { Desenvolvimento } \\
\text { do programa }\end{array}$ & $\begin{array}{l}\text { Currículo significativo, } \\
\text { complexidade, transversalidade } \\
\text { e realidade local. }\end{array}$ \\
\hline $\begin{array}{l}\text { Educação Pré- } \\
\text { Escolar }\end{array}$ & $\begin{array}{l}\text { Componente } \\
\text { Complementar } \\
\text { Optativo }\end{array}$ & $\begin{array}{l}\text { Conteúdo } \\
\text { programático }\end{array}$ & Natureza e Sociedade. \\
\hline $\begin{array}{l}\text { Educação } \\
\text { Ambiental }\end{array}$ & $\begin{array}{l}\text { Componente } \\
\text { Complementar } \\
\text { Optativo }\end{array}$ & Todo o programa & Todo o programa. \\
\hline
\end{tabular}

Características ambientais nos programas de disciplinas

Observamos então, que de tantas disciplinas oferecidas no curso de Pedagogia, apenas algumas trazem consigo, no seu planejamento, a fomentação da discussão acerca da temática ambiental. No entanto, fica claro também, a intenção de algumas dessas 
disciplinas de atingir a transversalidade proposta pelos PCN's, incluindo assim, os temas transversais em seus programas.

Podemos observar ainda nos componentes básicos profissionais, de maneira mais direta e transversal, aparecer as características educação ambiental, meio ambiente, terra, ar, água, solo, biodiversidade e ecologia, nos casos das disciplinas: Sociologia da Educação II, Psicologia da Educação II e Ensino de Ciências, o que, nesse último caso, já era esperado a dimensão ambiental estar inserida, por se tratar de disciplina específica de ciências naturais. Essa prática interdisciplinar e transversal objetiva superar a fragmentação do conhecimento. O que para (GUIMARÃES, 1995), é um importante enfoque a ser perseguido pelos educadores que se pretendem educadores ambientais, já que permite, pela compreensão mais globalizada do ambiente, trabalhar a interação em equilíbrio dos seres humanos com a natureza.

É possível encontrar ainda a dimensão ambiental inserida em disciplinas que não são cursadas por todos os alunos, já que se trata de componentes complementares optativos. No caso, a disciplina Educação Ambiental, que por se tratar da própria dimensão inserida na educação, traz em seu programa a contemplação de características próprias da dimensão. E também, a disciplina Educação Pré-Escolar, que evidencia dentro do seu conteúdo programático, o conteúdo Sociedade e Natureza. Essa seria então uma inserção da temática ambiental no estudo da prática educativa para as primeiras atividades pedagógicas.

Percebemos com isso, que a Educação Ambiental, já nos programas e ementas das disciplinas, assim como no PPP do curso de Pedagogia, se apresenta de forma clara em alguns momentos, porém ainda ínfima, no que diz respeito a atender ao caráter interdisciplinar e transversal proposto pelos PCN.

No questionário destinado aos professores, questões como compreensão sobre Meio Ambiente, conceito de Educação Ambiental, formas de trabalhar a EA e inserção da temática na disciplina lecionada, se fizeram presentes para que pudéssemos encontrar as respostas às perguntas que objetivamos durante este estudo.

Ao perguntarmos sobre o que os mesmos entendiam por Meio Ambiente, obtivemos respostas diversas como mostra o gráfico a seguir: 


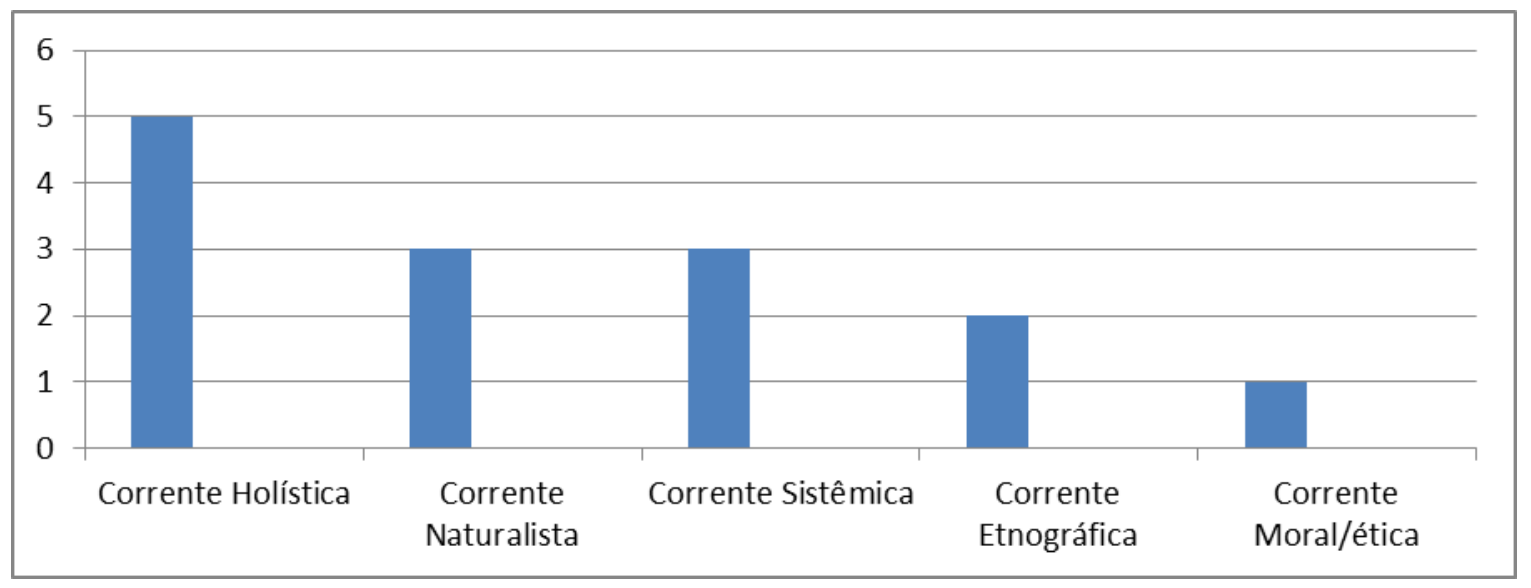

Concepção de Meio Ambiente dos professores.

De acordo com as correntes de concepções de Meio Ambiente (MA) de (SAUVÉ, 2005), a maioria das respostas se deram dentro da Corrente Holística, que tem como concepção de MA o Total, o Todo, O Ser; obtendo um enfoque mais holístico, orgânico, intuitivo. Podemos identificar essas características em uma das respostas que se apresenta:

Envolve tudo ao nosso redor. Tanto o meio construído, como o natural, onde é possível incluir, em uma mesma unidade de análise, movimentos, relações, que vem da natureza e das sociedades humanas. (Socioambiental).

Foi possível encontrar também respostas que se mostravam características das concepções Naturalista, que apresenta como concepção a natureza, no intuito de reconstruir uma ligação com a mesma: "Todo o ambiente sócio-natural onde vivemos, seres humanos, animais e vegetais"; Sistêmica, onde envidencia uma análise e síntese para uma visão global, capaz de compreender as realidades ambientais, tendo em vista decisões apropriadas: "O conjunto de condições bióticas e abióticas, além das relações sociais, culturais. Neste contexto, o homem é mais um elemento do meio, e por sua vez, interage com as condições ambientais, sociais, etc...”; Etnográfica, que tem como concepção o território, um lugar de identidade, uma relação da natureza com a cultura: "É o espaço onde vivemos, construimos, elaboramos e reelaboramos cultura"; e ainda uma resposta que mostrava o meio ambiente como objeto de valores, em uma concepção de corrente Moral/ética, como nos mostra a resposta a seguir:

É o conjunto de condições naturais, disposições psicológicas, condições sociais, determinações materiais e valores morais que influenciam a vida dos organismos vivos e dos homens e mulheres.

Rev. Eletrônica Mestr. Educ. Ambient. Rio Grande, v. 36, n. 2, p. 296 - 318, mai./ago. 2019. 
Através da descrição acima é verificado a especifidade da comprenssão dos professores acerca do conceito de meio ambiente, e que se aproxima das definições de (CARVALHO, 2002), quando afirma que o meio ambiente deve ser compreendido de uma forma holística, integrada e sistêmica", constituindo-se assim a idéia de transversalidade do saber.

Em termos conceituais e técnicos, lembramos que de acordo com a resolução CONAMA 306/2002: Meio Ambiente vem a ser o conjunto de condições, leis, influência e interações de ordem física, química, biológica, social, cultural e urbanística, que permite, abriga e rege a vida em todas as suas formas.

No próximo gráfico, encontramos as respostas dos professores acerca de como os mesmos enxergam a relação entre meio ambiente e educação.

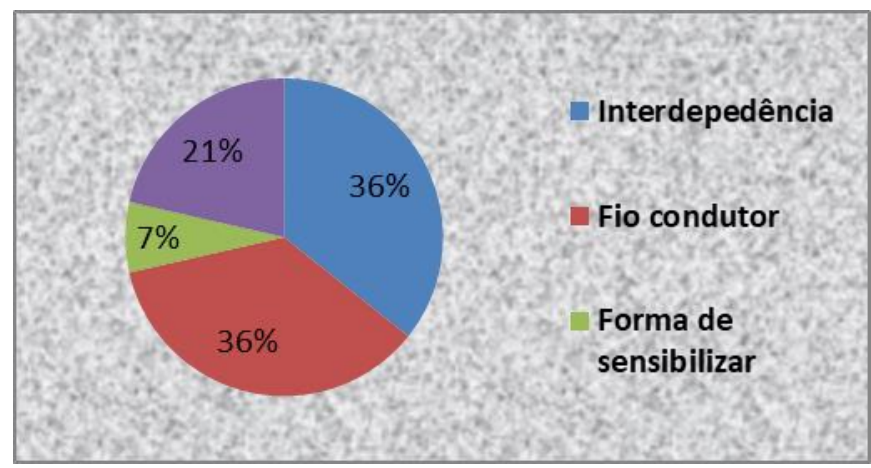

Relação entre meio ambiente e educação para os professores.

Como descrito no gráfico acima, grande parcela dos docentes (31\% ou cinco), afirma que entre educação e meio ambiente existe uma relação de interdependência, em que vemos transcrita nas falas: "Uma relação intrínseca, inseparável (...); e“(...) relação intrínseca, já que se faz necessário se perceber enquanto ser pertencente e responsável pelo meio em que se vive."

Vemos também que em boa parte ( $31 \%$ ou cinco), encontramos a afirmação de que esta relação (meio ambiente e educação) vem a ser um fio condutor. Onde temos: “(...) fio condutor entre o homem, a sociedade e a natureza para a resolução de problemas (...)”.

Ainda encontramos resposta que diz respeito a uma forma de sensibilização $(7 \%$ ou um), onde temos: "A educação atrelada ao meio ambiente pode melhorar e proteger o planeta (...) sensibilizar (...)”.

E por fim como resultado ( $21 \%$ ou três), ainda foi citado pelos docentes que a relação entre meio ambiente e educação perpassa por uma relação de diálogo entre ambas as partes, como vemos na transcrição:“(...) relações dialógicas das mais variadas aprendizagens se apresentam intrínsecas nestes dois campos do conhecimento." 
Em relação ao disposto acima, observamos que a dialogicidade é a essência da educação como prática da liberdade, como afirma Paulo Freire, que salienta ainda o diálogo como um fenômeno humano;

Se nos revela como algo que já poderemos dizer ser ele mesmo: a palavra. Mas, ao encontrarmos a palavra, na análise do diálogo, como algo mais que um meio para que ele se faça, se nos impõe buscar, também seus elementos constitutivos. (FREIRE, 2005, p.89)

Observamos ainda nas respostas, que em sua maioria, os professores, mesmo que inconscientes e não intencionados, estabelecem entre a educação e o meio ambiente, uma relação de interdisciplinaridade e transversalidade, já que suas respostas apresentam características como fio condutor, dialogicidade e interdependência. (LOUREIRO, 2006) afirma que para uma educação ambiental efetiva, é importante uma atitude dialógicodialética, que nos leve a um entendimento da unidade sintética do movimento dinâmico da vida e da sociedade na história natural.

Perguntamos então aos professores, o que os mesmos entendiam por Educação Ambiental, já que esperamos que esta última estivesse inserida de forma transversal em suas disciplinas. Para análise das respostas, utilizamos as categorias de EA já mencionadas na metodologia, para identificar as características das concepções que estes professores têm acerca da dimensão ambiental inserida na educação. $O$ gráfico a seguir nos revela o que os professores do curso de Pedagogia da UFPB, Campus I entendem por Educação Ambiental:

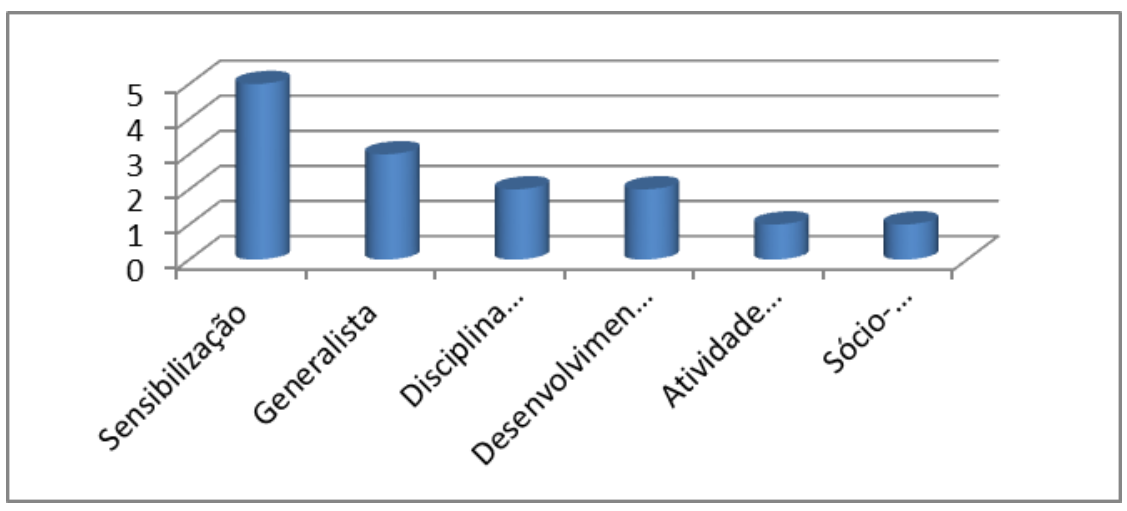

Concepção de Educação Ambiental dos professores.

Percebemos que a maior parte dos professores ainda concebe a EA como um ato de sensibilização. Não podemos negar ou evitar que a EA se estabeleça também como sensibilização ou conscientização através da educação em si, pois de fato a mesma se concebe dessa forma. Porém, para além de uma educação que sensibiliza, conscientiza e forma, a EA também se faz crítica, formando e reformulando conceitos e cidadãos que se 
pretendem ecologicamente corretos, e também, socialmente justos e politicamente atuantes, como nos remete (LAYRARGUES, 2006).

Encontramos também em boa parte das respostas, afirmações de EA como generalista, como podemos ver na transcrição: "Educação Ambiental é um processo contínuo, que envolve os aspectos biológicos, econômicos, políticos, ecológicos, sociais. Promotora de mudanças de comportamento, ela visa um meio à formação de uma nova cidadania ambiental."

Buscamos então, saber se os professores analisados já haviam desenvolvido algum projeto ou estudo na área ambiental, e se já, qual o nome e como se desenvolveu o projeto e/ou estudo. Vemos no gráfico a seguir, a resposta dos professores quanto aos que já desenvolveram algo:

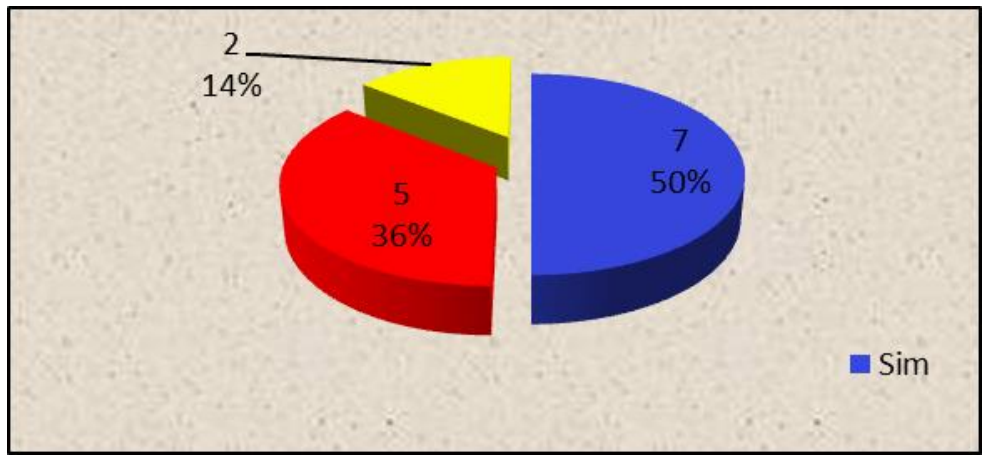

Professores que já desenvolveram projeto ou estudo na área ambiental.

Estes dados nos remetem a uma pergunta que contempla a necessidade de obter a informação se as disciplinas do Curso de Pedagogia contemplam projetos e/ou estudos na área de Educação Ambiental. Grande maioria (50\% ou sete) como mostra o gráfico acima, afirma que em algum momento de sua disciplina já desenvolveu um projeto e/ou estudo na dimensão ambiental. Ainda temos como parcela considerável, cerca de 36\% (cinco), que responderam não a pergunta, e 14\% (dois) que não responderam.

Entre os projetos e/ou estudos desenvolvidos pelos professores encontramos: propostas educativas com artes; EA e formação de professores; EA e populações tradicionais; EA no contexto da EJA (Educação de Jovens e Adultos); projetos reciclagem de lixo; resíduos sólidos; e ainda em artigo publicado sobre educação e transdisciplinaridade, revelando a diversidade na relação entre gênero e meio ambiente.

Em suma, as respostas nos mostram que apenas disciplinas voltadas à temática trabalham e/ou desenvolvem mais especificamente projetos ou assuntos relacionados à dimensão ambiental. Alguns professores ainda mencionaram que apenas se deparam com essa temática quando é o caso de algum aluno solicitar orientação para monografia voltada 
para a área, é o que identificamos na fala: "Atualmente o tema é discutido a partir da orientação de (TCC) de alunos de Pedagogia."

Assim notamos que a dimensão ambiental se encontra sendo pouco trabalhada nas formas de projetos ou trabalhos. De acordo com os PCN, a forma como os educadores devem trabalhar a temática Educação Ambiental se expressa da seguinte forma:

O trabalho com o tema meio ambiente deve ser desenvolvido visando-se proporcionar aos alunos uma grande diversidade de experiências, e ensinar-lhes formas de participação, para que possam ampliar a consciência sobre as questões relativas ao meio ambiente e assumir deforma independente e autônoma, atitudes e valores voltados à sua proteção e melhoria. Como fazer? As especificidades são muitas para cada grupo, cada região, e essas diferentes realidades deverão ser consideradas em cada escola pelo professor, para que se possam selecionar os melhores conteúdos, as melhores formas de se trabalhar a questão ambiental (MEC, 1997, p. 71)

Sendo assim, entendemos que as orientações didáticas são sugeridas de forma a fornecerem suporte aos professores, e garantia para que os mesmos venham a desenvolver trabalhos sobre o meio ambiente, abordando questões significativas, dentro da realidade em que os alunos já se encontram inseridos.

Assim como no questionário dos professores, buscamos no questionário dos alunos, compreender as concepções de meio ambiente e educação ambiental tantos dos alunos que estavam no início do curso, quanto os que já estavam perto de concluir.

Por início, buscamos identificar o que os alunos entendiam por Educação, para conhecer se os mesmos reconheciam alguma característica que remetesse à dimensão ambiental. Para análise das respostas, criamos categorias para identificar os conceitos dos alunos, de forma que essas respostas se aproximassem de tais categorias. Foram estas: Crescimento moral e intelectual; Ensinar e aprender; Transmissão de conhecimentos; Formação da cidadania; Fenômeno social; Comportamento; e Indefinido. Vejamos no gráfico a seguir, como se deram as respostas:

Rev. Eletrônica Mestr. Educ. Ambient. Rio Grande, v. 36, n. 2, p. 296 - 318, mai./ago. 2019. 


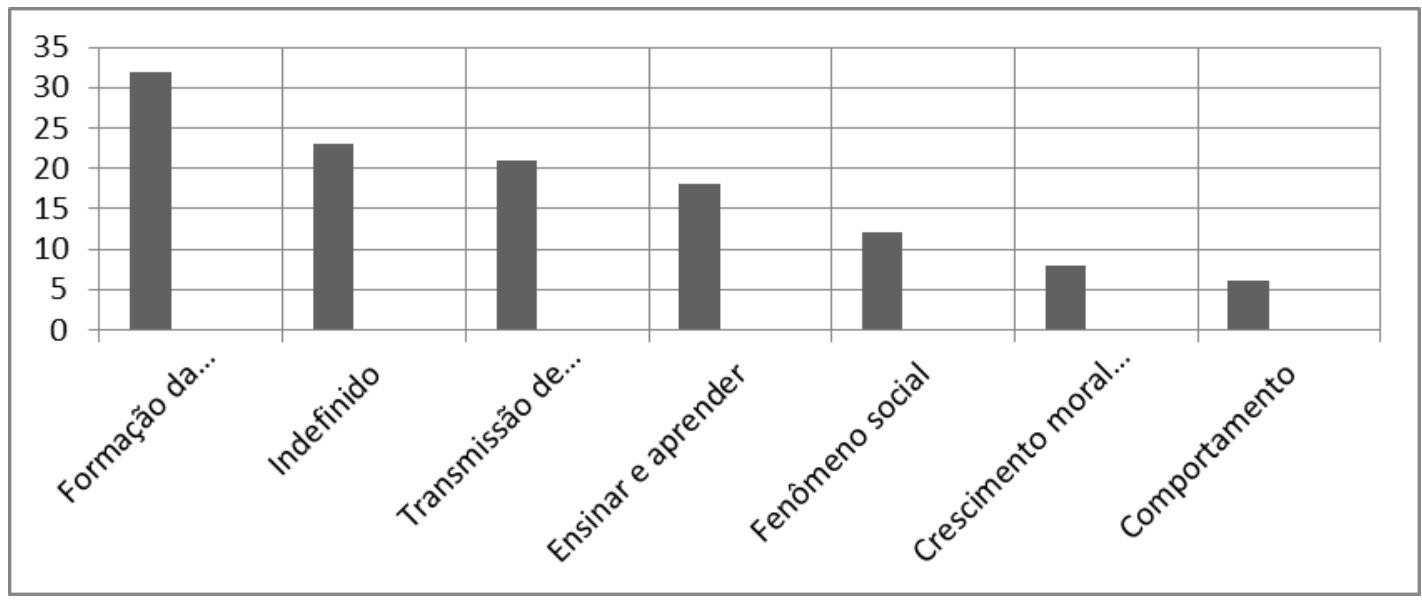

Definição de Educação pelos alunos.

Observemos que a grande maioria - 32 associaram suas respostas a uma definição de Formação da cidadania, com características como processo de formação do indivíduo para inserção na sociedade e construção da sua cidadania. Podemos identificar isso na resposta a seguir: "É uma forma de ensinar, e formar bons cidadãos para a sociedade, seguindo alguns métodos de ensinamentos".

Podemos observar nos resultados também, que boa parte dos alunos não conseguem definir exatamente o que seria Educação. Isso acontece com expressões confusas ou mal formuladas, como: a base de tudo, processo de instruir, a base da vida, ou ainda declarando que não consegue realmente definir, como vemos na fala: "A educação tem um campo muito amplo, por isso, para mim não consigo defini-lo”.

Há também os que enxergam a Educação de uma maneira mais tradicional, como apenas transmissão de conhecimentos, até mesmo ampliando essa concepção, pois alguns declararam poder ser concebida em ambiente escolar e/ou não escolar. Essa concepção é colocada geralmente como um processo onde se concebe ou é passado de professores para alunos os conhecimentos, ou até mesmo através da sociedade. Observemos a resposta: " $O$ conhecimento que nos é repassado, desde que começamos a aprender no decorrer das nossas vidas".

Dentre as respostas, observamos também, aquelas que obtinham concepções mais amplas de Educação, como um Fenômeno social. Essas concepções geralmente são colocadas como um fenômeno, que acontece tanto nas escolas, como em qualquer ambiente, onde se é transmitido e ao mesmo tempo construído conhecimentos, valores, conceitos, saberes. Vemos como exemplo de resposta com essa concepção na transcrição: "Educação é tudo que adquirimos ao logo de nossas vidas e de modo mais especializado (cientifico), dentro de ambientes escolares".

Rev. Eletrônica Mestr. Educ. Ambient. Rio Grande, v. 36, n. 2, p. 296 - 318, mai./ago. 2019. 
Foi possível observar ainda nas respostas, características que identificam a Educação como uma questão de comportamento dos indivíduos. Identificamos essa concepção na resposta: "É algo que tem haver com o bom comportamento pessoal, normalmente uma pessoa bem educada é uma pessoa bem comportada”.

Sobre Educação, consideramos o que nos coloca Brandão:

"Não há uma forma única nem um único modelo de educação; a escola não é o único lugar onde ela acontece e talvez nem seja o melhor; o ensino escolar não é a sua única prática e o professor profissional não é seu único praticante". (BRANDÃO, 1993, p. 9)

Vemos então a educação como um fenômeno social, que se estabelece não somente na escola, e não somente transmitida pela figura do professor, mas elaborada e construída a partir de todos os atores sociais.

Porém, em nenhuma das respostas pudemos observar características da educação como um campo interdisciplinar onde se pode pensar epistemologicamente sobre os vários saberes. O que acarretaria em uma abertura a problematização e construção do trabalho com a dimensão ambiental.

Como foi feito aos professores, questionamos também os alunos sobre os mesmos entendem por Meio Ambiente. Para análise, utilizamos também as concepções de Meio Ambiente de (SAUVÉ, 2005). E diferente do que observamos nas respostas dos professores, onde a concepção predominante foi a Corrente holística, onde se concebe o Total, o Todo, O Ser, nas respostas dos alunos tantos dos primeiros períodos, quanto dos últimos, obtivemos em sua grande maioria, a Corrente Naturalista. Como observamos no gráfico a seguir:

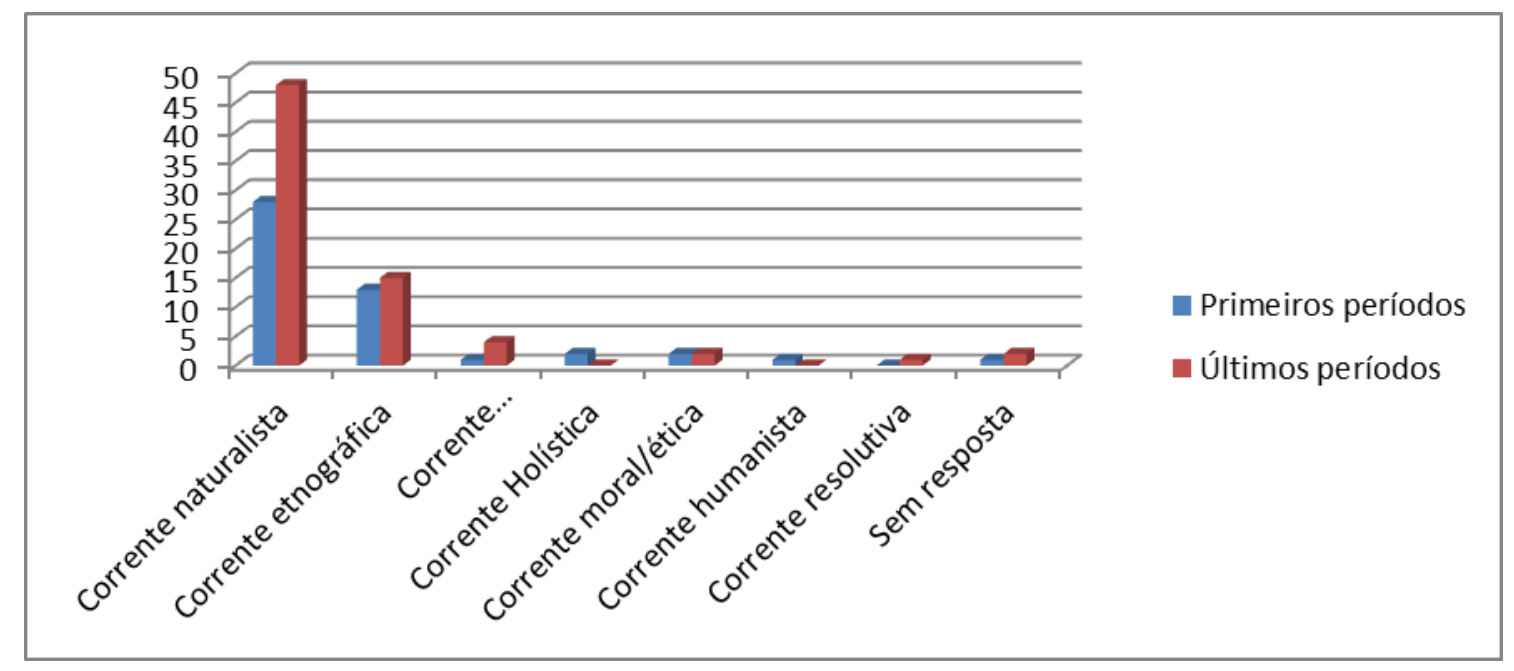

Gráfico 9: Concepção de Meio Ambiente dos alunos. 
Observamos através dos dados obtidos, que os alunos do curso de Pedagogia, do início ao fim do curso, em sua maioria, obtêm uma concepção de MA apenas como Natureza. Vemos isso transcrito na resposta de dos alunos, tanto do início, quanto do fim do curso:

"Meio ambiente é a natureza e seus seres vivos". (Início do curso)

"É o conjunto de seres vivos e ecossistemas". (Início do curso)

"O meio ambiente está ligado a tudo o que nos cerca; água, ar, alimento, solo, natureza, seres vivos, etc.”. (Final do curso)

Podemos observar ainda uma parte considerável de respostas que se enquadram na Corrente etnográfica, levando em consideração o Território, um Lugar de identidade entre natureza e cultura. Verificamos assim nas respostas: "É o meio que vivemos, que compreende o homem, a sua relação com os outros homens e com a natureza, e tudo que a compõe" (Início do curso). Ou ainda: "É o espaço físico, seja natural ou não, que nos relacionamos. Nesta relação, nos fazemos enquanto seres humanos, mas, também modificamos o meio ambiente" (Final do curso).

Percebemos então, que do início para o final do curso, a concepção de MA considerado como a natureza não foi ampliada. E ainda podemos observar que esta é uma concepção que vem de tempos anteriores e permanece da mesma forma.

Questionamos também como os alunos enxergam a relação entre Meio Ambiente e Educação. Diferente das respostas dos professores que nos remeteram a características como: interdependência, fio condutor, relação de dialogicidade; nos questionários dos alunos, tanto dos primeiros quanto dos últimos períodos, vimos que estas características se apresentaram de forma efêmera, predominando quase em sua totalidade, características que remetiam a uma forma de sensibilização, conscientização dos indivíduos para conservação e preservação da natureza. Podemos observar essas concepções nas respostas a seguir:

"Devemos educar as pessoas à preservar o meio ambiente evitando a poluição e suas consequências: aquecimento global, efeito estufa, afim de proteger o planeta Terra".

"A educação ajuda na conscientização das pessoas com respeito à preservação do meio ambiente, e a conhecê-lo".

"O meio ambiente só vai sobreviver, se educarmos as nossas sociedades a se conscientizar de que devemos, cuidar de nossa natureza com carinho, plantar árvores, preservar os rios, não jogar lixo nos lugares indevidos”.

Notemos que as características das respostas dos professores que evidenciavam um caráter interdisciplinar e transversal na relação entre MA e Educação, não são encontradas nas respostas dos alunos, colocando a EA mais uma vez com aspectos reducionistas, já encontrados nas respostas sobre o conceito de Meio Ambiente. Loureiro nos aponta que:

Rev. Eletrônica Mestr. Educ. Ambient. Rio Grande, v. 36, n. 2, p. 296 - 318, mai./ago. 2019. 
"São construções que partem de premissas frágeis, que resultam em dicotomias falsas e que precisam ser superadas em busca de um posicionamento paradigmático complexo, dialético e crítico, que nos leve a um entendimento da unidade sintética do movimento dinâmico da vida e da sociedade na história natural". (LOUREIRO, 2006, P. 118)

\section{Considerações finais}

Ao analisarmos o Projeto Político Pedagógico do curso, podemos constatar que o mesmo apresenta de maneira simplificada o eixo norteador transversal Meio Ambiente. Que poucas são as características contidas no mesmo que revelam a dimensão ambiental, evidenciando mais características das quais fazem parte da Educação Ambiental, como pluralismo de concepções, justiça social, qualidade de vida, diferentes formas de pensar e atuar sobre a realidade e a complexidade.

Quanto aos componentes curriculares do curso, encontramos uma disciplina que contempla a dimensão ambiental, intitulada Corpo, Ambiente e Educação, e uma disciplina optativa chamada Educação Ambiental. Vemos assim, uma incoerência com os Parâmetros Curriculares Nacionais, quando afirmam que esta não deve se apresentar como disciplina, mas de forma interdisciplinar e transversal. E ainda analisando o ementário desses componentes curriculares, pudemos encontrar de forma clara, porém ínfima, a temática inserida em algumas disciplinas do curso. Dessa forma, estabelecendo parceria com as orientações dos PCN na busca da construção de educadores que se pretendem inserida nas diversas dimensões da educação.

Quando analisado o questionário dos professores, foi possível constatar que os mesmos conseguem obter uma boa concepção do que vem a ser meio ambiente, e que os mesmos vêem a relação entre este último e a educação como uma questão dialógica e de interdependência, o que evidencia o caráter interdisciplinar e transversal da relação. Porém, quando questionados sobre como entendiam a educação ambiental, a maioria se mostrou perceber como uma forma de sensibilização, o que evidencia uma concepção reducionista da EA, não estabelecendo a mesma como um ato político, crítico, reflexivo.

No entanto, quando fizemos as mesmas perguntas aos alunos do curso, podemos observar que os mesmos, em sua maioria, concebiam o meio ambiente como algo relacionado estritamente à natureza. Que vêem a relação entre meio ambiente e educação como uma forma de sensibilização e conscientização dos indivíduos a favor da preservação da natureza. E que entendem a educação ambiental como uma fora de conscientização e preservação. Percebemos assim, que diferente de uma visão mais sólida dos professores, os 
alunos ainda enxergam as relações educacionais e ambientais, como algo restrito à consciência de que é preciso preservar a natureza.

Procurando então descobrir o envolvimento dos professores e alunos em projetos e estudos na área, questionamos aos professores se já desenvolveram algo, 50\% destes afirmaram já ter realizado algum trabalho envolvendo a dimensão ambiental. Porém, na resposta dos alunos observamos que apenas três alunos responderam já ter visto algum tema ambiental trabalhado nas aulas, e ainda, que estes foram apresentados na disciplina Ensino de Ciências, ou ainda na própria disciplina Educação Ambiental.

Concluímos assim que, mesmo os professores questionados já percebendo de certa forma a dimensão ambiental inserida na educação, colocando isto de forma transversal e relacionada a interdisciplinaridade, de fato, esta, vem sendo pouco encontrada no âmbito das discussões curriculares, evidenciando que a relação entre currículo e os temas transversais ainda encontra-se pouco efetivado no curso de Pedagogia da UFPB.

Percebemos também que os alunos encontram-se aquém das discussões e da problemática ambiental, não percebendo esta sendo desenvolvida pelo curso, nem pelos professores em sua maioria, revelando que a formação inicial dos pedagogos se mostra pouco inserida na transversalidade dos temas ambientais, e da reflexão crítica e reflexiva da educação ambiental.

Contudo, reafirmamos a certeza de que esta caminhada encontra-se em passos de fundamentação e efetivação de práticas educativas reflexivas, de que a preocupação com a formação inicial dos educadores vem sendo cada vez mais observada no âmbito das discussões políticas e pedagógicas do nosso país, e de que estas começam a ser observadas e inseridas nas ações educativas escolares e não escolares.

\section{Referências}

BARDIN, Laurence. Análise de conteúdo. São Paulo: Edições 70, 2011.

BRANDÃO, Carlos Rodrigues. O que é educação. 28. ed. São Paulo: Brasiliense, Coleção Primeiros Passos, 1993.

BRANDÃO, Zaia. A Crise dos Paradigmas e a Educação. São Paulo: Cortez. 1981.

CARVALHO, Isabel Cristina de Moura. A Invenção Ecológica. Narrativas e Trajetórias da Educação Ambiental no Brasil. 2. ed. Porto Alegre: Editora UFRGS, 2002. 
CARVALHO, Isabel Cristina de Moura. A questão ambiental e a emergência de um campo de ação político-pedagógica. In_Sociedade e meio ambiente: a educação ambiental em debate / LOUREIRO, Carlos Frederico Bernardo; LAYRARGUES, Philippe Pomier; CASTRO, Ronaldo Souza de (Orgs.). 3. Ed. São Paulo: Cortez, 2002.

\section{CONAMA, CONSELHO NACIONAL DO MEIO AMBIENTE. Resolução CONAMA}

$\mathbf{N}^{\mathbf{0}}$ 306/2002 - "Estabelece os requisitos mínimos e o termo de referência para realização de auditorias ambientais" - Data da edição: 05/07/2002 - Publicação DOU: 19/07/2002

DURKHEIM, Émile. Educação e sociologia. 11. ed. São Paulo: Melhoramentos, 1978.

FERREIRA, Nilda Teves. Cidadania - uma questão para a educação. Rio de Janeiro: Nova Fronteira, 1993.

FRANCO, Maria Laura Publisi Barbosa. Análise do conteúdo. 3. ed. Brasília: Liber Livro Editora, 2008.

FREIRE, Paulo. Pedagogia da Autonomia: Saberes necessários à prática educativa. São Paulo: Paz e Terra ,1997.

FREIRE, Paulo. Pedagogia do Oprimido. 42. ed. Rio de Janeiro. Paz e terra, 2005.

GUIMARÃES, Mauro. A dimensão ambiental na educação. Campinas, SP: Papirus, 1995.

LAYRARGUES, Philippe Pomier. Muito além da natureza: educação ambiental e reprodução social. In_CASTRO, Ronaldo Souza de; LAYRARGUES, Philippe Pomier; LOUREIRO, Carlos Frederico Bernardo. (Orgs.). Pensamento complexo, dialética e educação ambiental. São Paulo: Cortez, 2006.

LIMA, A. J. Ecologia humana. Petrópolis: Vozes, 1984.

LOUREIRO, Carlos Frederico Bernardo. Problematizando conceitos: contribuição à práxis em educação ambiental. In_CASTRO, Ronaldo Souza de; LAYRARGUES, Philippe Pomier; LOUREIRO, Carlos Frederico Bernardo. (Orgs.). Pensamento complexo, dialética e educação ambiental. São Paulo: Cortez, 2006.

Ministério da Educação e do Desporto/Secretaria do Ensino Fundamental. Parâmetros Curriculares Nacionais- Meio Ambiente. Brasília: MEC/SEF, 1996.

SATO, Michèle. Apaixonadamente pesquisadora em educação ambiental. In: Educação Teoria e Prática. Rio Claro, v. 9, n. 16/17, p. 24-35, 2001.

SAUVÉ, Lucie. Uma cartografia das correntes em educação ambiental. In_ Educação ambiental: pesquisa e desafios. Sato, Michèle; Carvalho, Isabel Cristina Moura. (Orgs.). Porto Alegre: Artmed, 2005. 
Rev. Eletrônica Mestr. Educ. Ambient. Rio Grande, v. 36, n. 2, p. 296 - 318, mai./ago. 2019. E-ISSN 1517-1256 